
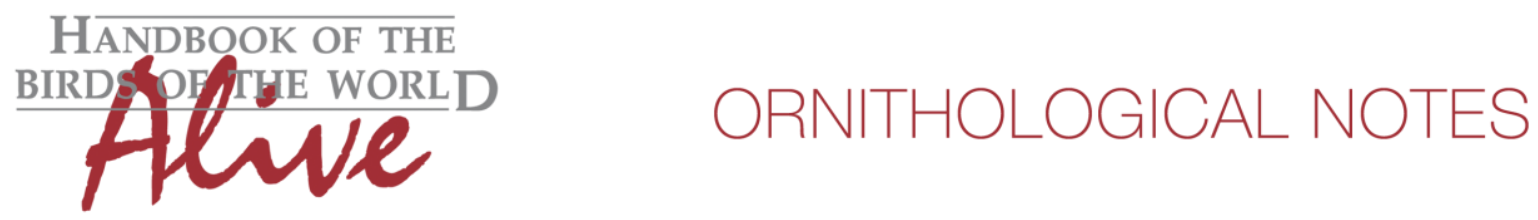

\title{
Notes on the vocalizations of Tawny Antpitta (Grallaria quitensis)
}

Peter Boesman

In the following we briefly analyze and compare voice of the different races of Tawny Antpitta (Grallaria quitensis). We also try to quantify the extent of any vocal differences using the criteria proposed by Tobias et al. (2010), as a support for taxonomic review. We have made use of sound recordings available on-line from Xeno Canto (XC).

There are only a few recordings available for the races other than quitensis. Based on these, it appears that loudsong of the 3 races is quite different (Fig. 1):

quitensis 3 evenly spaced notes 'tip..tuu..tuu'

atuensis 3 notes, last note after shorter pause bisyllabic and rising 'tip..tuu.tuee'

alticola 4 notes, last 3 notes in rhythmic sequence 'tip..pur.whe-tuu'

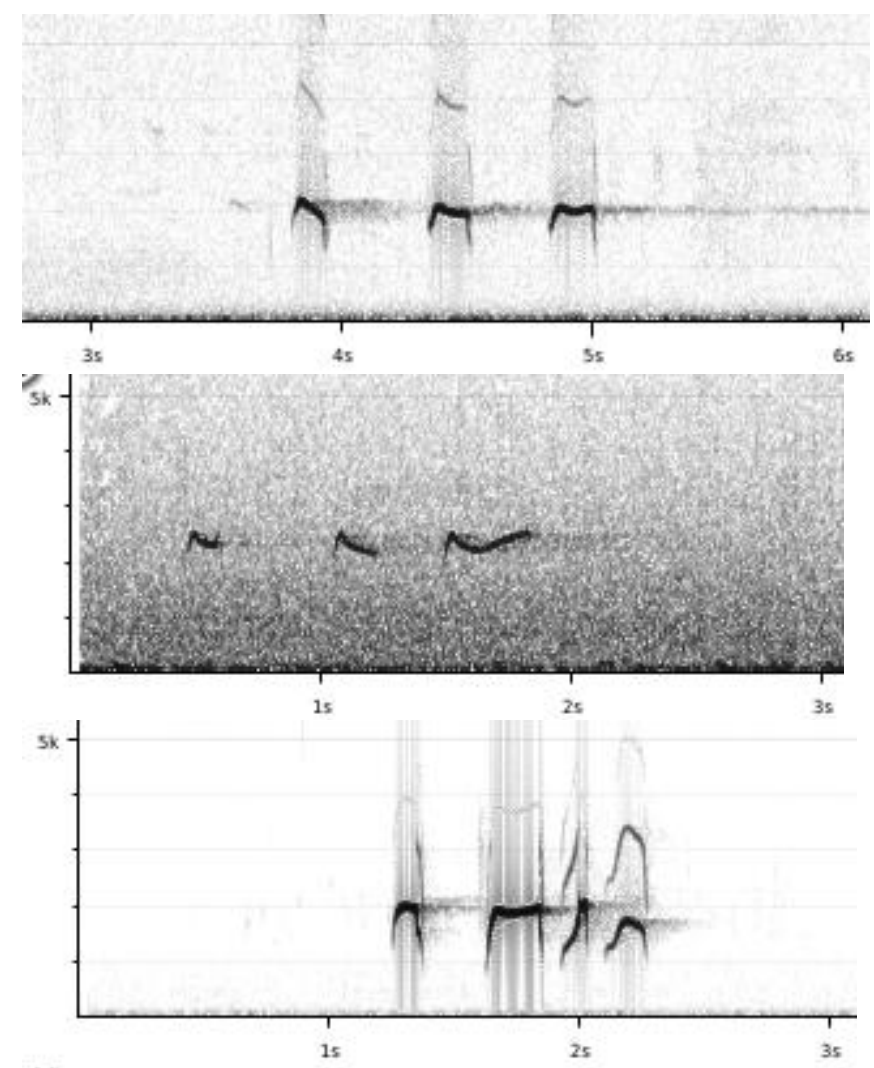

Figure 1: from top to bottom: loudsong of quitensis, atuensis and alticola

We have made some measurements for some basic sound parameters, with following results: 


\section{HANDBOOK OF THE

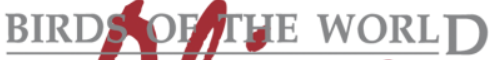 Alue}

$\begin{array}{llll} & \begin{array}{l}\text { quitensis } \\ (n=8)\end{array} & \begin{array}{l}\text { atuensis } \\ (n=3)\end{array} & \begin{array}{l}\text { alticola } \\ (n=1)\end{array} \\ \text { \# notes } & 3 & 3 & \\ \text { min. pause } & 0.26-0.35 \mathrm{~s} & 0.18-0.24 \mathrm{~s} & 4 \\ \text { max. note length } & 0.17-0.23 \mathrm{~s} & 0.32-0.34 \mathrm{~s} & 0.25 \mathrm{~s} \\ \text { min note length } & 0.10-0.16 \mathrm{~s} & 0.14-0.2 \mathrm{~s} & 0.11 \mathrm{~s} \\ \text { max. freq. } & 1960-2200 \mathrm{~Hz} & 2400 \mathrm{~Hz} & 1980 \mathrm{~Hz} \\ \text { min. mid freq. } & 1800-1900 \mathrm{~Hz} & 2050-2100 \mathrm{~Hz} & 1500 \mathrm{~Hz}\end{array}$

Assuming a larger sample size confirms these data, scoring would give:

atuensis differs from quitensis by long and rising end note (score 2 ) and higher pitch (score 1). Total score 3.

alticola differs from quitensis by a 4 note song with short pauses between last 3 notes (score 4) resulting in a rhythmic phrase, and also by reaching lower frequencies (score 1). Total score 5 .
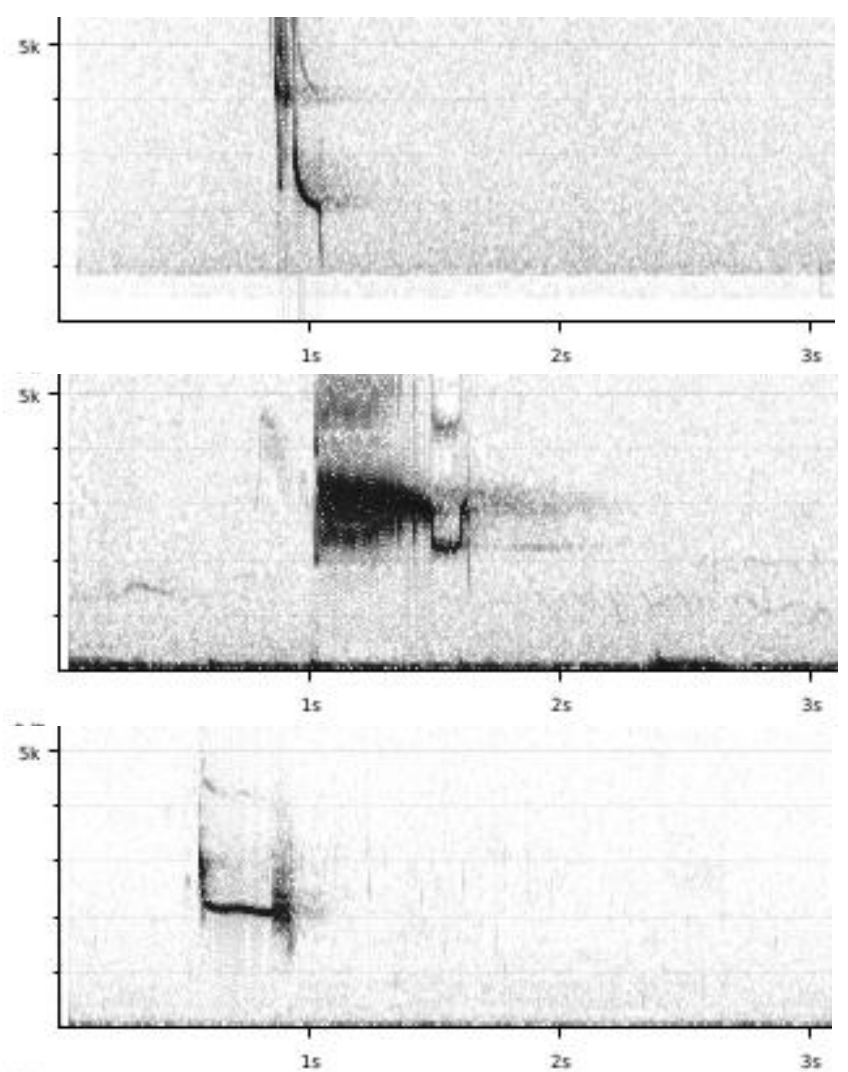

Figure 2: from top to bottom: commonest call of quitensis, atuensis and alticola 

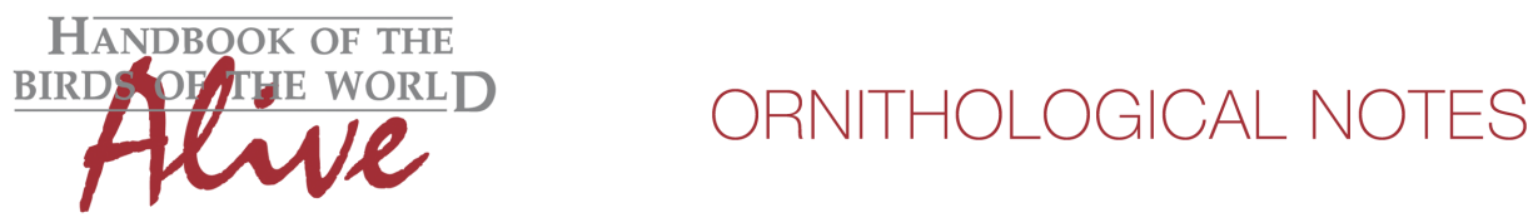

As the most common call note also seems to differ between the 3 races (Fig. 2), with especially atuensis very different, we have made also here some measurements:

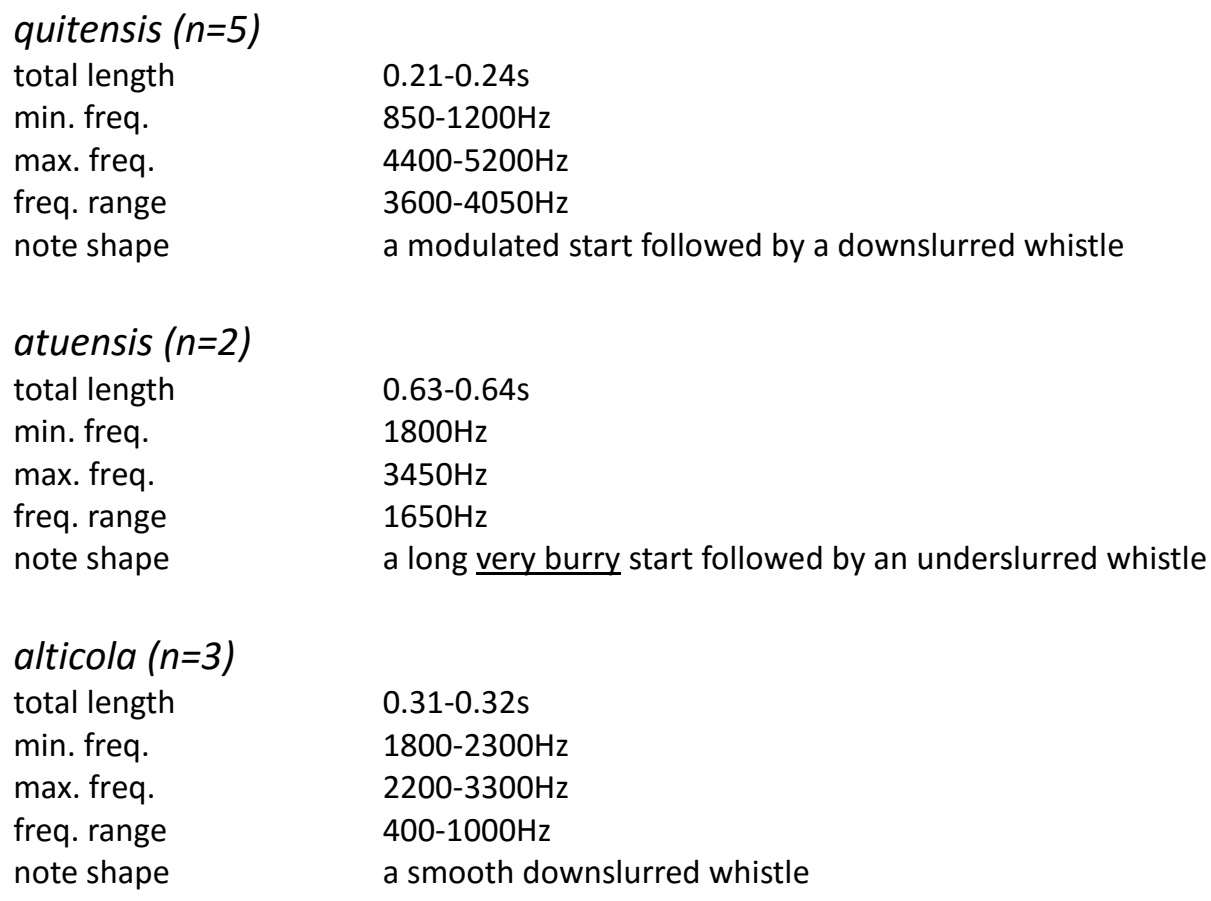

note shape

a smooth downslurred whistle

Main differences of atuensis vs. quitensis: atuensis has longer note length (score 3), smaller frequency range (score 2-3) and lower max. frequency (score 1-2), and a very distinct note shape. -> total score 5-6

Main differences of atuensis vs. alticola: atuensis has longer note length (score 3), higher frequency range (score 2), and a very distinct note shape -> total score 5

We can thus conclude that there are major vocal differences between all three races, both in loudsong and call note.

This note was finalized on 13th July 2015, using sound recordings available on-line at that moment. We would like to thank in particular the many sound recordists who placed their recordings for this species on XC: Roger AhIman, Nick Athanas, Peter Boesman, Allen Chartier, Oswaldo Cortes, Niels Krabbe, Dan Lane, Bernabe Lopez-Lanus, John V. Moore, Leonardo Ordoñez, Bob Planqué, Jeisson Poveda, Andrew Spencer, Mark Todd and WillemPier Vellinga. 


\section{References}

Tobias, J.A., Seddon, N., Spottiswoode, C.N., Pilgrim, J.D., Fishpool, L.D.C. \& Collar, N.J. (2010). Quantitative criteria for species delimitation. Ibis 152(4): 724-746.

\section{Recommended citation}

Boesman, P. (2016). Notes on the vocalizations of Tawny Antpitta (Grallaria quitensis). HBW Alive Ornithological Note 72. In: Handbook of the Birds of the World Alive. Lynx Edicions, Barcelona. (retrieved from http://www.hbw.com/node/931959 on 17 May 2016). 